\title{
Digital GPS Signal Generator for L1 Band
}

\author{
Kota Solomon Raju, Y. Pratap and P. Bhanu Prasad \\ Central Electronics Engineering Research Institute (CEERI) / Council of Scientific and \\ Industrial Research (CSIR) Pilani-333031, India \\ solomon@ceeri.ernet.in, pratap.sost.iiit@gmail.com, bhanulceeri.ernet.in
}

\begin{abstract}
This paper deals with the generation of GPS signals using FPGA based Xilinx System Generator 9.2. We have considered L1 frequency band as it is mainly used for commercial, civil aviation and other purposes. Once the GPS signals are generated in the simulated laboratory environment we can test the proper working of multichannel GPS receiver which is an extension of this project. After we obtain accurate laboratory results, we can go for real GPS signals. The board that has been used for the hardware implementation is Lyrtech SFF-SDR board, which is having three functional layers. The bottom layer is the digital signal-processing layer, middle layer is the ADAC MASTER III layer and the upper layer is RF layer having a transmission and receiving capacity of $1 \mathrm{GHz}$. This will lead to the development of indigenous digital GPS signal generator using reconfiguration.
\end{abstract}

\section{KEY WORDS}

GPS, FPGA, multichannel, SFF-SDR, ADAC MASTER III, RF, reconfiguration.

\section{INTRODUCTION}

GPS stands for Global Positioning System and it was started in the year 1973 by the US department of defense. It was made commercial for civil aviation in the early 1990's. GPS is a satellite based navigation system, which is used to find the position of an object across the earth by giving its coordinates. Currently GPS consists of 32 satellites of which 24 are for working and the rest eight are kept spare to replace any of these 24 satellites in case of malfunction or damage to them. These 24 satellites revolve around the earth surface in six predetermined orbits each orbit having four satellites. The satellites are not placed equidistant in a given orbit. Each orbit makes an angle of $60^{\circ}$ with the equator of the earth so as to complete total $360^{\circ}$. The orbital radius is $26560 \mathrm{~km}$ and time taken for one complete revolution is $11 \mathrm{hrs} 57 \mathrm{mins}$ and 57.26 secs [1]. In this paper, implementation of digital GPS signal generator using Xilinx system generator 9.2 has been dealt. First the GPS signal has been explained followed by each and every component of GPS signal. Then each component has been built using Xilinx system generator 9.2 and tested and finally complete GPS signal generator has been built and tested on hardware using Lyrtech SFFSDR board. 
Signal \& Image Processing : An International Journal (SIPIJ) Vol.3, No.6, December 2012

\section{GPS SIGNAL}

GPS signals are modulated signals, which are transmitted by the GPS satellites in the UHF band of $500 \mathrm{MHz}$ to $3 \mathrm{GHz}$ over two frequencies, i.e. L1 and L2 driven by a common clock of 10.23 MHz. The frequencies for the L1 and L2 are as shown below [1]:

$$
\begin{aligned}
& \mathrm{L} 1=1575.42 \mathrm{MHz}=154 \times 10.23 \mathrm{MHz} \\
& \mathrm{L} 2=1227.60 \mathrm{MHz}=120 \times 10.23 \mathrm{MHz}
\end{aligned}
$$

The GPS signals are a combination of three main parts namely the carrier frequency, navigation data and the spreading sequence namely the C/A code and P code. The carrier frequencies for the L1 and L2 band are stated above. The navigation data is the main component that has to be actually transmitted because it contains information about the satellite orbits [2]. The C/A code stands for coarse acquisition, which is useful in detecting from which satellite the signal is coming and $\mathrm{P}$ code is used to track the signals once the signals have been acquired. The signal structure for a particular GPS satellite ' $\mathrm{k}$ ' is given as [2]:

$$
\begin{aligned}
\mathrm{S}^{\mathrm{k}}(\mathrm{t})=\sqrt{2 \mathrm{Pc}} & \left(\mathrm{C}^{\mathrm{k}}(\mathrm{t}) \emptyset \mathrm{D}^{\mathrm{k}}(\mathrm{t})\right) \cos \left(2 \pi \mathrm{fL}_{1} \mathrm{t}\right)+\sqrt{2 \mathrm{P}_{\mathrm{PL} 1}}\left(\mathrm{P}^{\mathrm{k}}(\mathrm{t}) \emptyset \mathrm{D}^{\mathrm{k}}(\mathrm{t})\right) \sin \left(2 \pi \mathrm{fL}_{1} \mathrm{t}\right) \\
& +\sqrt{2 \mathrm{P}_{\mathrm{PL} 2}}\left(\mathrm{P}^{\mathrm{k}}(\mathrm{t}) \emptyset \mathrm{D}^{\mathrm{k}}(\mathrm{t})\right) \sin (2 \pi \mathrm{fL} 2 \mathrm{t})
\end{aligned}
$$

Here we can observe that the GPS satellite signal is a combination of various power levels of its different components. We can see the power levels for both L1 and L2 and also navigation data which is to be transmitted is shown as $\mathrm{D}^{\mathrm{k}}$. The power levels for the components are shown in the table below [1].

Table 1. Power Level of GPS Signals

\begin{tabular}{|c|c|c|}
\hline & $\mathrm{P}$ & $\mathrm{C} / \mathrm{A}$ \\
\hline $\mathrm{L} 1$ & $-133 \mathrm{dBm}$ & $-130 \mathrm{dBm}$ \\
\hline $\mathrm{L} 2$ & $-136 \mathrm{dBm}$ & $-136 \mathrm{dBm}$ \\
\hline
\end{tabular}

Binary Phase Shift Keying (BPSK) modulation has been used for the signal propagation. The main reason for going for BPSK modulation, when other modulation techniques are available, is that the transmitter and receiver are much easier to build and the demodulator is able to withstand highest level of noise before it starts giving error [3]. The Doppler frequency for the carrier frequency is about $4.9 \mathrm{KHz}$ and that for C/A code is $3.2 \mathrm{~Hz}$. Doppler frequency is the change in the observed frequency of a source due to the relative motion between the source and the receiver [4].

\section{GPS SIGNAL AND BPSK MODULATION FOR L1 FREQUENCY}

The pictorial representation of GPS signal structure is shown below [5]: 


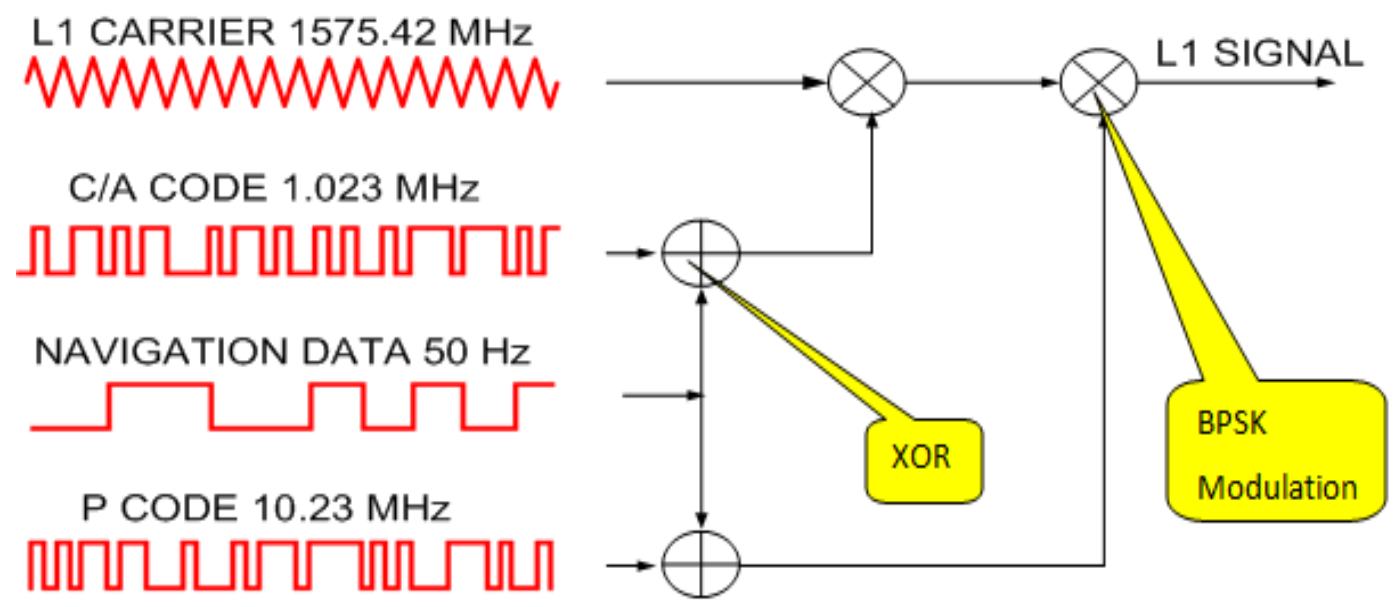

Fig. 1. GPS Signal Structure

The above picture shows the various components of GPS signal for L1 band. First component is the carrier frequency having $1575.42 \mathrm{MHz}$ driven by a common frequency of $10.23 \mathrm{MHz}$. The $\mathrm{C} / \mathrm{A}$ code is having a frequency of $1.023 \mathrm{MHz}$ and it repeats itself every $1 \mathrm{~ms}$ [2].

$$
t=\frac{1023}{1.023 \times 10^{6}}=1 \mathrm{~ms}
$$

1023 is the number of chips in the C/A code which tells us about the phase. The P code is having a frequency of $10.23 \mathrm{MHz}$ and it repeats itself every GPS week, which starts around midnight of Saturday or Sunday. The third component is the navigation data which contains all the information about the satellite orbits and pseudo range from which satellite position and finally user position can be found out by using triangulation method. It has a data rate of $50 \mathrm{bps}$. In order for a modulated signal to propagate, all the signal components should be an integral multiple of a frequency which is clearly shown here, as 1575.42, 1.023 and 10.23 are integral multiples of 1.023. The effect of BPSK modulation is as shown below [2]: 
Signal \& Image Processing : An International Journal (SIPIJ) Vol.3, No.6, December 2012

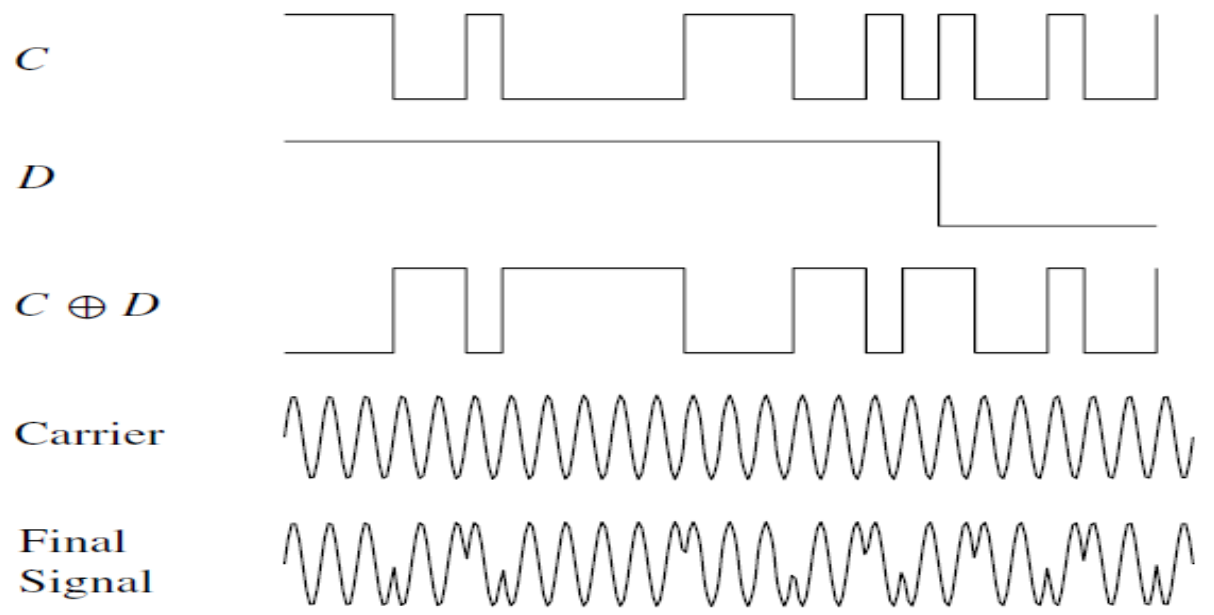

Fig. 2. Effect of BPSK Modulation on Carrier Signal

The above figure shows the effect of BPSK modulation on the carrier signal. First the C/A code and Navigation data signals are XORed by using modulo- 2 operation. The resultant signal is multiplied with the carrier signal. It can be observed wherever there is a change in the XORed signal, a $180^{\circ}$ phase shift occurs in the final signal.

\section{C/A CODE GENERATOR FOR GPS SATELLITES}

The main purpose of a coarse acquisition (C/A) code is to find, at the GPS receiver side, from which satellite the signal is coming. Each satellite transmits a C/A code, which is unique for that satellite. The pictorial representation of C/A code generator is as shown below [1]:

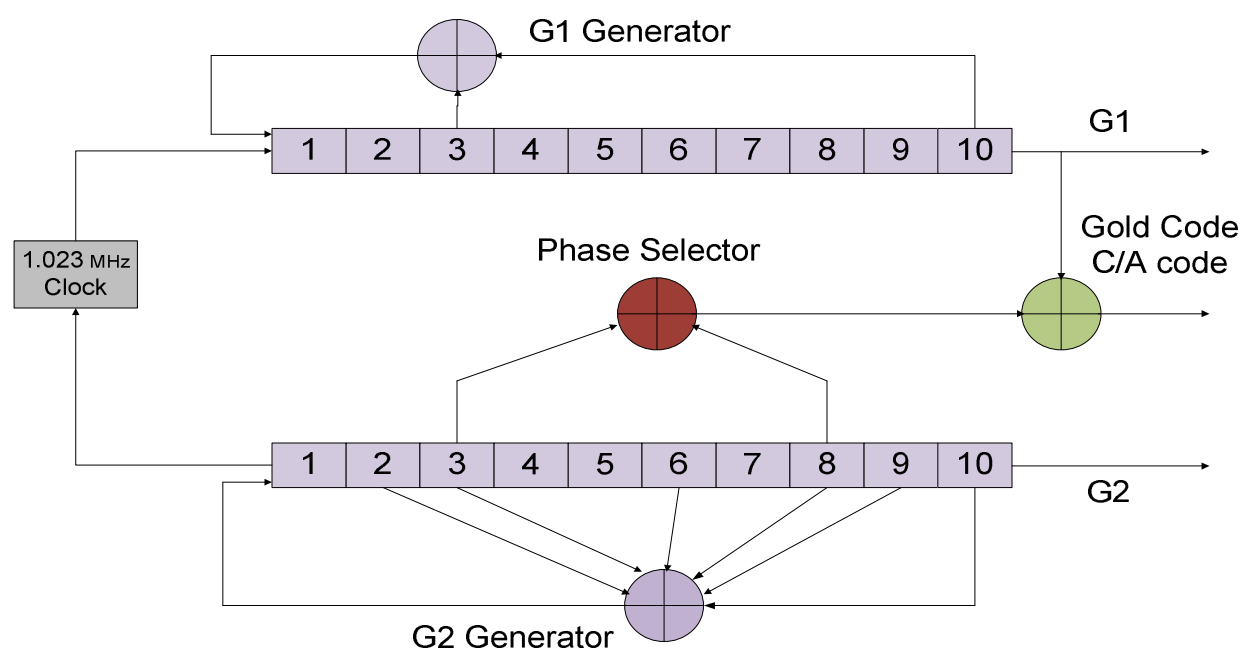

Fig. 3. C/A code Generator for Satellite 31 
Signal \& Image Processing : An International Journal (SIPIJ) Vol.3, No.6, December 2012

C/A code generator for satellite 31 consists of two linear feedback shift registers (LFSRs) each consisting of ten unit cells or delay units, which are initialized to a value of 1 which indicates the phase. LFSR generates a maximal length sequence of $\mathrm{N}=2^{\mathrm{n}}-1$ elements, where $\mathrm{n}=10$. These two LFSRs are based on the GPS polynomials given as:

$$
\begin{aligned}
& \mathrm{G} 1=1+\mathrm{x}^{3}+\mathrm{x}^{10} \\
& \mathrm{G} 2=1+\mathrm{x}^{2}+\mathrm{x}^{3}+\mathrm{x}^{6}+\mathrm{x}^{8}+\mathrm{x}^{9}+\mathrm{x}^{10}
\end{aligned}
$$

The powers of the above polynomials indicate the tapping or the delays at that particular unit cell in the LFSRs. The tappings in each LFSR are XORed and the output is given as feedback to the first unit cell. These LFSRs are driven by a common clock of $1.023 \mathrm{MHz}$. In order to find out the signal from a particular satellite, phase selector is used. Different satellites have different phase selectors which show the delay in the C/A code generation for each satellite. This further helps in identifying the satellite signals. The different phase selectors for all the GPS satellites are shown as below [1]:

\begin{tabular}{|c|c|c|c|}
\hline $\begin{array}{l}\text { Satellite ID } \\
\text { Number }\end{array}$ & $\begin{array}{ll}\text { GPS } & \text { PRN } \\
\text { Signal } & \\
\text { Number } & \end{array}$ & $\begin{array}{ll}\text { Code } & \text { Phase } \\
\text { selection } & \end{array}$ & $\begin{array}{l}\text { Code Delay } \\
\text { Chips }\end{array}$ \\
\hline 1 & 1 & $2 \oplus 6$ & 5 \\
\hline 2 & 2 & $3 \oplus 7$ & 6 \\
\hline 3 & 3 & $4 \oplus 8$ & 7 \\
\hline 4 & 4 & $5 \oplus 9$ & 8 \\
\hline 5 & 5 & $1 \oplus 9$ & 17 \\
\hline 6 & 6 & $2 \oplus 10$ & 18 \\
\hline 7 & 7 & $1 \oplus 8$ & 139 \\
\hline 8 & 8 & $2 \oplus 9$ & 140 \\
\hline 9 & 9 & $3 \oplus 10$ & 141 \\
\hline 10 & 10 & $2 \oplus 3$ & 251 \\
\hline 11 & 11 & $3 \oplus 4$ & 252 \\
\hline 12 & 12 & $5 \oplus 6$ & 254 \\
\hline 13 & 13 & $6 \oplus 7$ & 255 \\
\hline 14 & 14 & $7 \oplus 8$ & 256 \\
\hline 15 & 15 & $8 \oplus 9$ & 257 \\
\hline 16 & 16 & $9 \oplus 10$ & 258 \\
\hline 17 & 17 & $1 \oplus 4$ & 469 \\
\hline 18 & 18 & $2 \oplus 5$ & 470 \\
\hline 19 & 19 & $3 \oplus 6$ & 471 \\
\hline
\end{tabular}

Table 2. C/A Code Phase Assignment 
Signal \& Image Processing : An International Journal (SIPIJ) Vol.3, No.6, December 2012

\begin{tabular}{|l|l|l|l|}
\hline 20 & 20 & $4 \oplus 7$ & 472 \\
\hline 21 & 21 & $5 \oplus 8$ & 473 \\
\hline 22 & 22 & $6 \oplus 9$ & 474 \\
\hline 23 & 23 & $1 \oplus 3$ & 509 \\
\hline 24 & 24 & $4 \oplus 6$ & 512 \\
\hline 25 & 25 & $5 \oplus 7$ & 513 \\
\hline 26 & 26 & $6 \oplus 8$ & 514 \\
\hline 27 & 27 & $7 \oplus 9$ & 515 \\
\hline 28 & 28 & $8 \oplus 10$ & 516 \\
\hline 28 & 28 & $1 \oplus 6$ & 859 \\
\hline 30 & 30 & $2 \oplus 7$ & 860 \\
\hline 31 & 31 & $3 \oplus 8$ & 861 \\
\hline 32 & 32 & $4 \oplus 9$ & 862 \\
\hline- & 33 & $5 \oplus 10$ & 863 \\
\hline- & 34 & $4 \oplus 10$ & 950 \\
\hline- & 35 & $1 \oplus 7$ & 947 \\
\hline- & 36 & $2 \oplus 8$ & 948 \\
\hline- & 37 & $4 \oplus 10$ & 950 \\
\hline & & & \\
\hline
\end{tabular}

The C/A code generator model developed using Xilinx System Generator 9.2 is as shown in figure 4 .

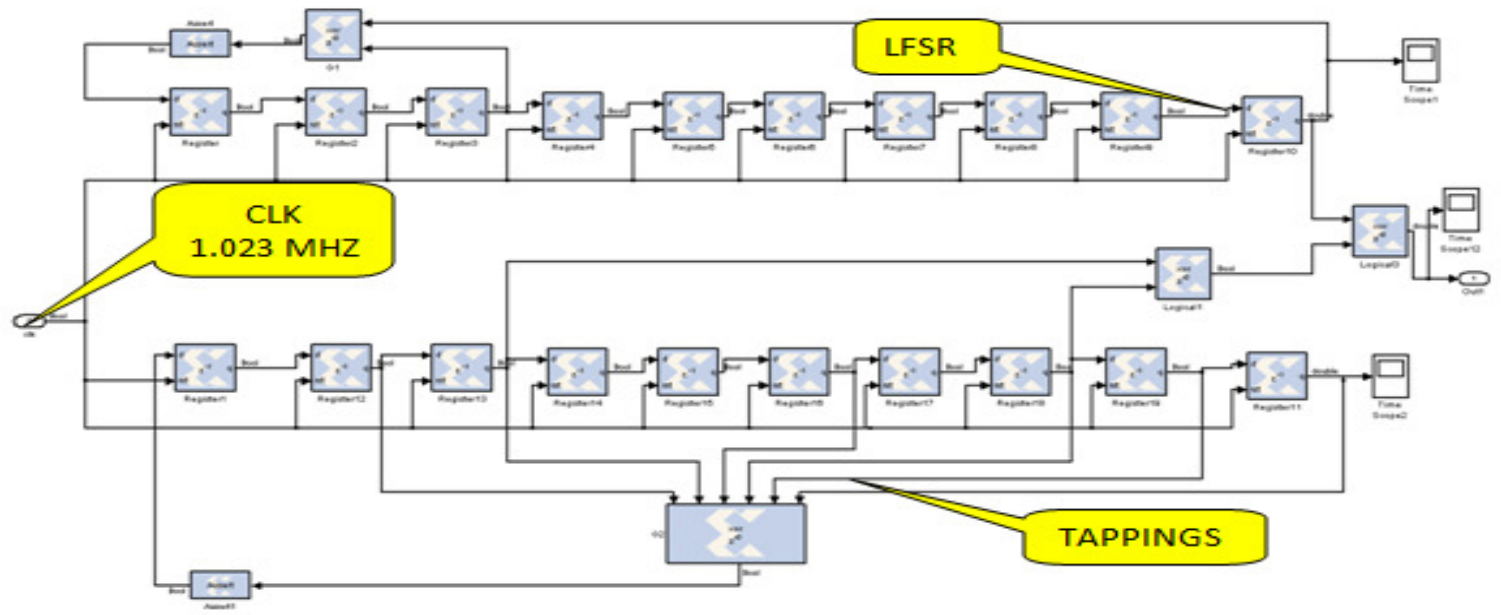

Fig. 4. C/A Code Generator for Satellite 31 
Signal \& Image Processing : An International Journal (SIPIJ) Vol.3, No.6, December 2012

Here we have used Xilinx block sets to develop the model for the satellite 31. For each LFSR we have taken 10-memory unit or delay unit blocks from the Xilinx block sets. Each of these blocks is initialized to a binary value of 1 which denotes the initial phase. As can be seen, these blocks are driven by a clock of $1.023 \mathrm{MHz}$. These two linear feedback shift registers are designed based upon the two polynomials G1 and G2 explained earlier. The tappings in the figure 4 indicate the delay which are XORed and given as feedback to the first memory unit of the respective LFSR.

We have also developed a model for coarse acquisition (C/A) codes for all the satellites as can be seen in figure 5. This model is partly based on the sub model developed by Dick Benson in his complete GPS receiver model [6]. In this model, phase selectors of all the satellites are multiplexed so that we can handle C/A codes from any given satellite at a given instant of time. As can be seen, VPSS (video processing sub system) block of TMS320DM6446SoC (Davinci processor) is used. This block is very important for hardware implementation of any model as it helps in hardware interface of the FPGA(Xilinx) blocks with the DSP on the hardware.

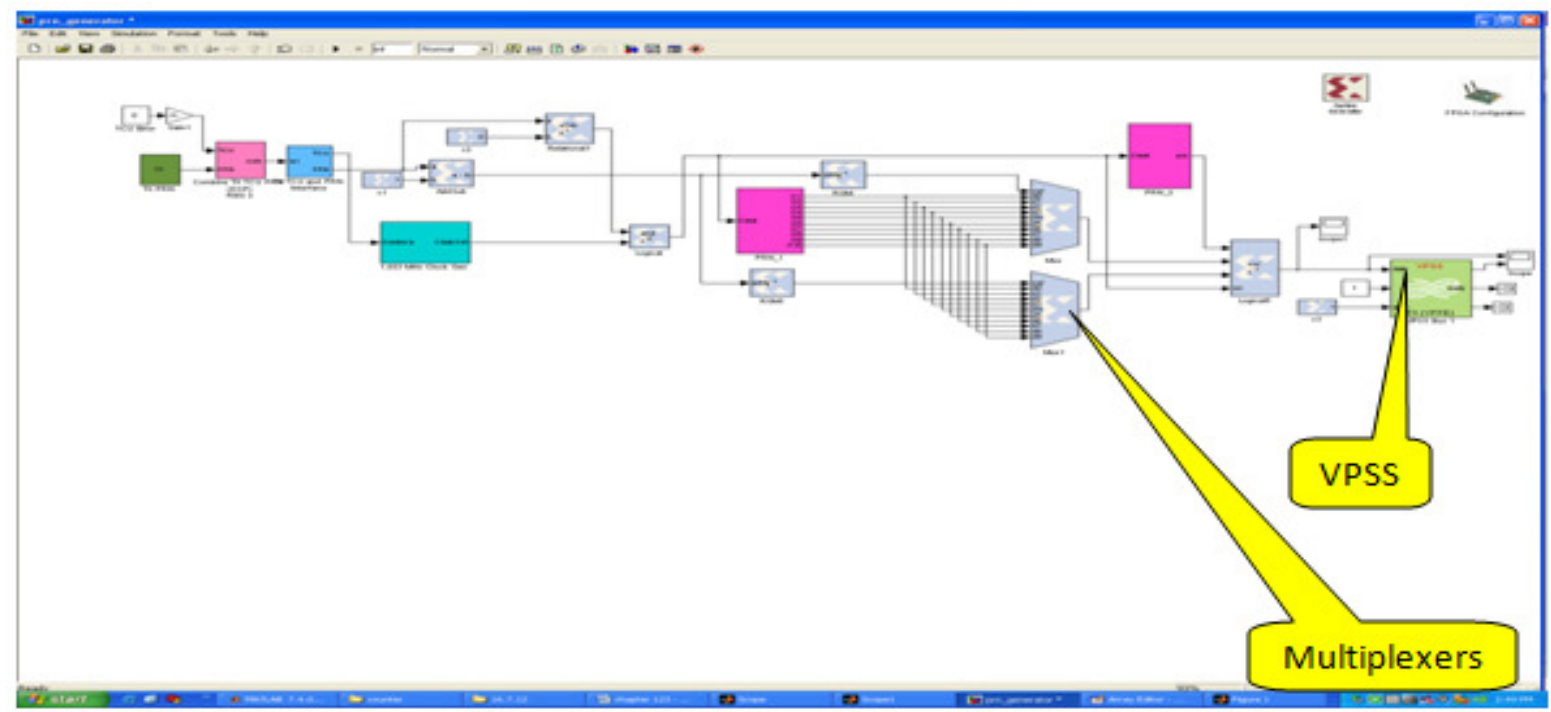

Fig. 5. C/A Code Generator for all the Satellites

\section{P CODE}

The P code, as already mentioned, is used to track the satellite signals once the GPS receiver acquires them. The $\mathrm{P}$ code is generated by using four linear feedback shift registers which are paired. These LFSRs can be denoted as X1A, X1B, X2A, and X2B. One PRN (pseudorandom noise) sequence has 15345000 chips and a period of 1.5 seconds, the other has 15345037 chips, and the difference is 37 chips [1]. P code repeats itself every GPS week starting around midnight of Saturday/Sunday. The LFSRs are based on the equations given by the GPS society as below [7]:

$$
\begin{aligned}
& \mathrm{X} 1 \mathrm{~A}=1+\mathrm{x}^{6}+\mathrm{x}^{8}+\mathrm{x}^{11}+\mathrm{x}^{12} \\
& \mathrm{X} 1 \mathrm{~B}=1+\mathrm{x}^{1}+\mathrm{x}^{2}+\mathrm{x}^{5}+\mathrm{x}^{8}+\mathrm{x}^{9}+\mathrm{x}^{10}+\mathrm{x}^{11}+\mathrm{x}^{12} \\
& \mathrm{X} 2 \mathrm{~A}=1+\mathrm{x}^{1}+\mathrm{x}^{3}+\mathrm{x}^{4}+\mathrm{x}^{5}+\mathrm{x}^{7}+\mathrm{x}^{8}+\mathrm{x}^{9}+\mathrm{x}^{10}+\mathrm{x}^{11}+\mathrm{x}^{12} \\
& \mathrm{X} 2 \mathrm{~B}=1+\mathrm{x}^{2}+\mathrm{x}^{3}+\mathrm{x}^{4}+\mathrm{x}^{8}+\mathrm{x}^{9}+\mathrm{x}^{12}
\end{aligned}
$$


Signal \& Image Processing : An International Journal (SIPIJ) Vol.3, No.6, December 2012

As in the case of C/A code the powers in the equations indicate the tappings to the memory unit cells. These are XORed and given as feedback to the first unit cell of each LFSR. The model developed for $\mathrm{P}$ code using system generator 9.2 is shown below in figure 6 .

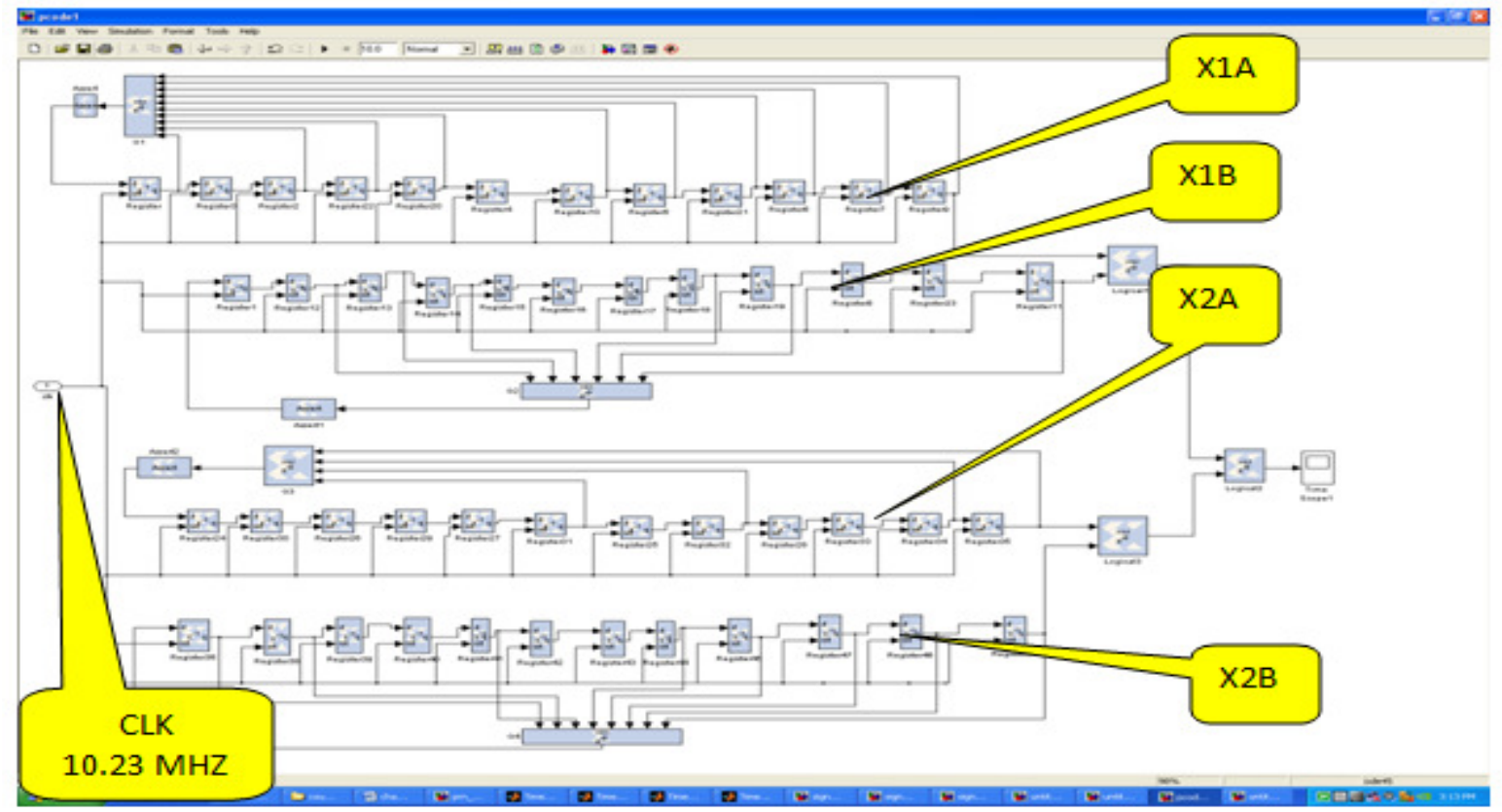

Fig. 6. P Code Generator

The unit cells or the memory units in the LFSRs are initialized to the values given by the GPS society and are given below:

$\mathrm{X} 1 \mathrm{~A}$ is initialized at 000100100100 and $\mathrm{X} 1 \mathrm{~B}$ is initialized at 010101010100 .

$\mathrm{X} 2 \mathrm{~A}$ is initialized at $\mathbf{1 0 0 1 0 0 1 0 0 1 0 1}$ and $\mathrm{X} 2 \mathrm{~B}$ is initialized at 010101010100.

\section{NAVIGATION DATA}

The basic structure of a navigation data is shown in fig. 7. [1].

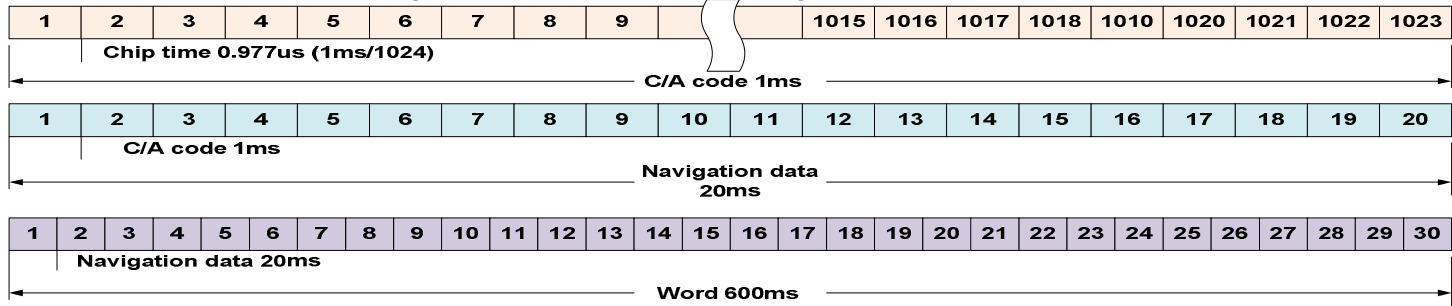

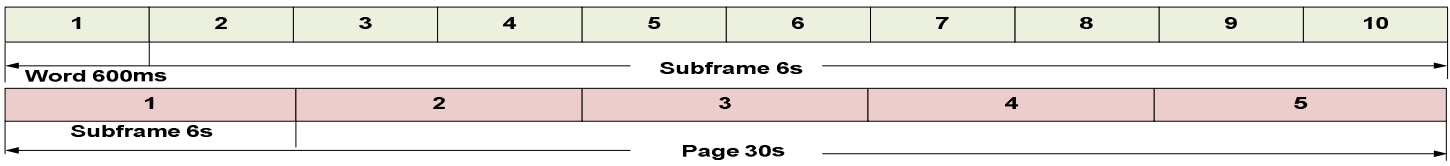

\begin{tabular}{|c|c|c|c|c|c|c|c|c|c|c|c|c|c|c|c|c|c|c|c|c|c|c|c|c|}
\hline 1 & 2 & 3 & 4 & 5 & 6 & 7 & 8 & 9 & 10 & 11 & 12 & 13 & 14 & 15 & 16 & 17 & 18 & 19 & 20 & 21 & 22 & 23 & 24 & 25 \\
\hline \multicolumn{10}{|c|}{12.5 minutes } \\
\hline
\end{tabular}

Fig. 7. Navigation Data Structure 
Signal \& Image Processing : An International Journal (SIPIJ) Vol.3, No.6, December 2012

Navigation data is transmitted in the L1 frequency at a bit rate of $50 \mathrm{bps}$. It repeats itself every 20 $\mathrm{ms}$. So the time taken for transition of one navigation bit is equivalent to the time of transition of $20 \mathrm{C} / \mathrm{A}$ codes, since one C/A code is transmitted every $1 \mathrm{~ms}$. The basic unit in a navigation data is the frame which consists of 1500 bits. Each frame is divided into 5 sub frames of 300 bits each. Each sub frame can be divided into 10 words of 30 bits each. The time for transmission of one sub frame is 6 secs and in a frame first 3 sub frames repeat themselves and the rest two sub frames have same structure but different data ( 25 different versions). So the time for transmission of one entire navigation message is $5 * 6 * 25$ i.e. 750 secs or twelve and half minutes.

The sub frame 1 consists of satellite clock and health data. It tells us at what time the signals is transmitted from the satellite and also whether the data is correct or not. Sub frame 2 and 3 contain information about satellite ephemeris data i.e. it gives us information about the satellite orbits that are used for finding satellite positions. Sub frames 4 and 5 contain almanac data i.e. ephemeris and clock data with reduced precision.

\section{GPS SignAL GENERATOR MODEL USING XILINX}

The model developed for complete GPS signal generator is shown figure 8 .

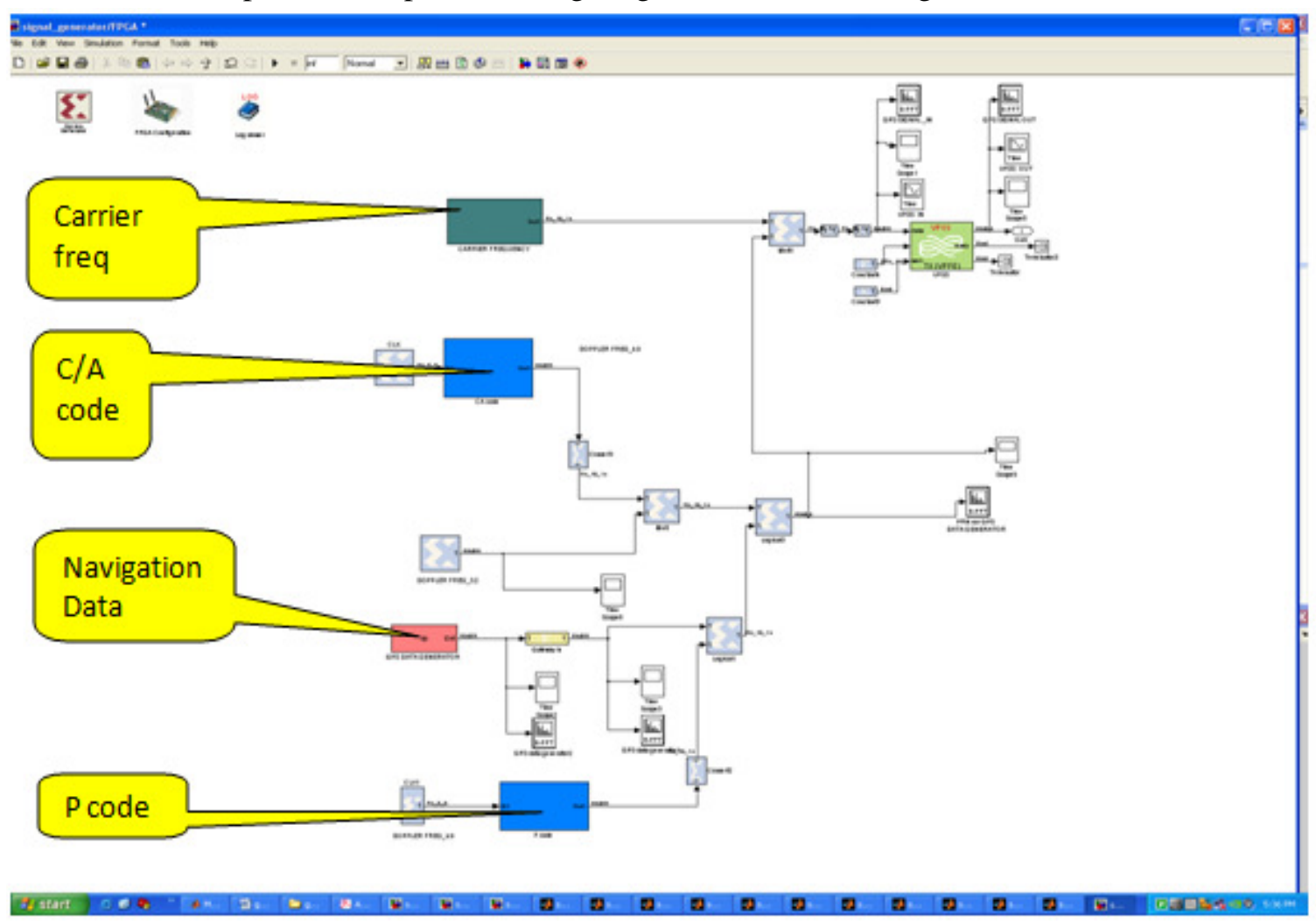

Fig. 8. GPS Signal Generator

The various components of GPS signal are shown in fig. 8. Here the C/A code and the navigation data are XORed using modulo-2 operation. We can generate the navigation data by using a free running counter or a count limited one. We can also use a pulse generator for generating the 
Signal \& Image Processing : An International Journal (SIPIJ) Vol.3, No.6, December 2012

navigation data. Navigation data is having a bit rate of 50 bps. The result is XORed with $\mathrm{P}$ code. Finally BPSK modulation is done between this resultant signal and the carrier frequency which is having a frequency of $1575.42 \mathrm{MHz}$. The resultant final GPS signal is sent to the hardware by VPSS (video processing sub system).

\section{HARDWARE AND SOFTWARES USED}

The implementation is done using Lyrtech SFF-SDR board[8]. It is conceived and designed to be used for developing software defined radios. The board is composed of three layers: digital processing, ADAC MASTER III and RF module. The digital processing module has Virtex-4 SX35 FPGA and a TMS320DM6446SoC to implement custom IP and acceleration functions with varying requirements from one protocol to another supported on the same hardware. The ADAC Master III layer has an inbuilt ADC and DAC. ADC is having resolution of 14 bit and sampling frequency of 125 MSPS while DAC is having a resolution of 16 bits and a sampling frequency of 500 MSPS. The RF layer is having a transmission capacity of $1 \mathrm{GHz}$. The board is as shown in figure 9.

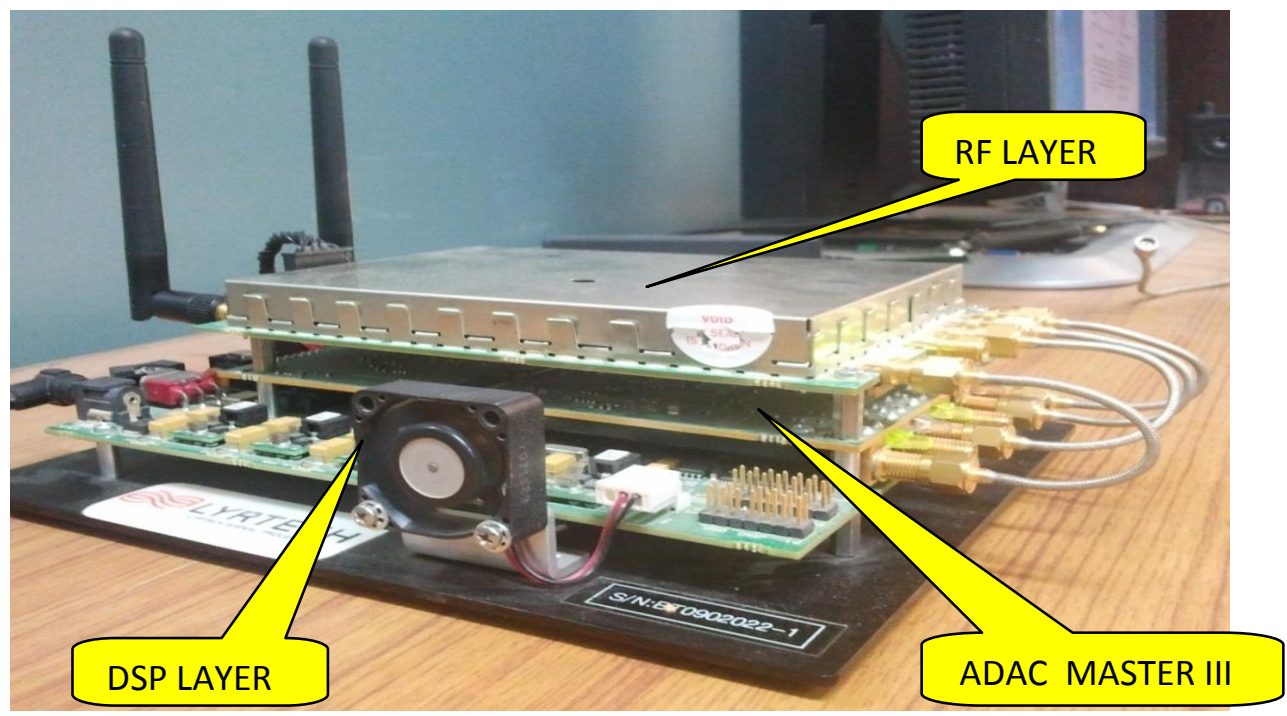

Fig. 9. Lyrtech SFF-SDR board

The software packages used are Matlab 2007a, Xilinx ISE 9.2, System Generator 9.2 and ADP 3.2.0 by Lyrtech.

\section{RESULTS AND FUTURE WORK}

Generation of carrier frequency:

Figure 10 shows the generation of the carrier frequency $1575.42 \mathrm{MHz}$ for L1 band. We have taken a common clock of $10.23 \mathrm{MHz}$ for generating this frequency. On this carrier frequency navigation data and C/A code are modulated by using the BPSK modulation. 
Signal \& Image Processing : An International Journal (SIPIJ) Vol.3, No.6, December 2012

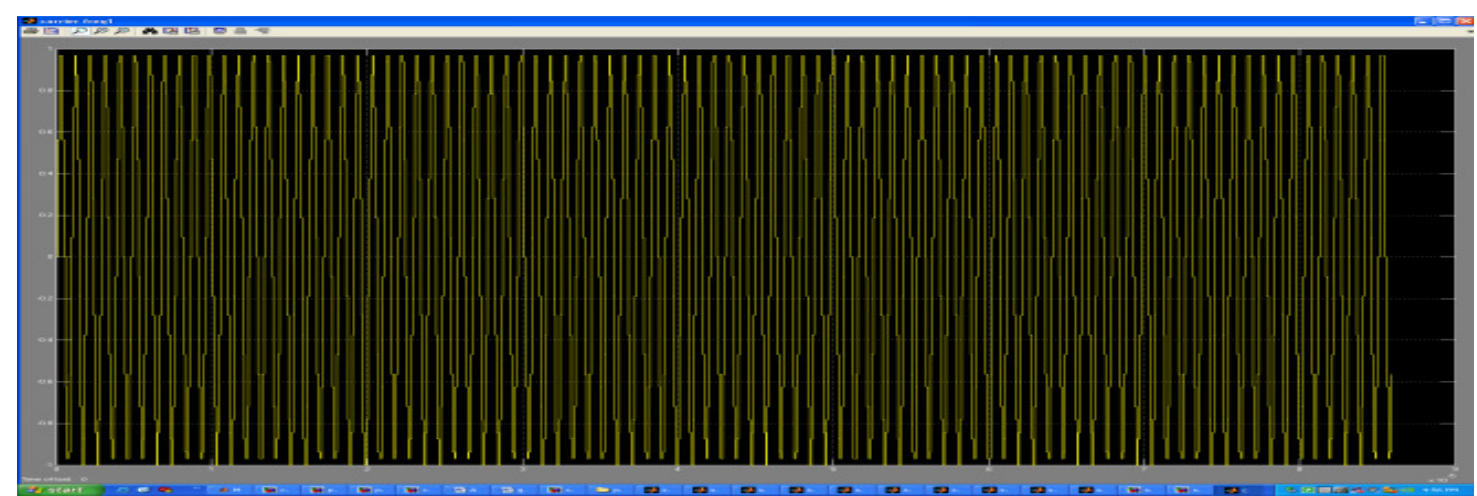

Generation of C/A (Gold)code:

Fig. 10. Carrier Frequency

Here we have generated the Gold code or the C/A code for the satellite 31. The phase selector used for this operation is a modulo- 2 combination of $3^{\text {rd }}$ and $8^{\text {th }}$ unit cells of second Linear Feedback Shift Register.

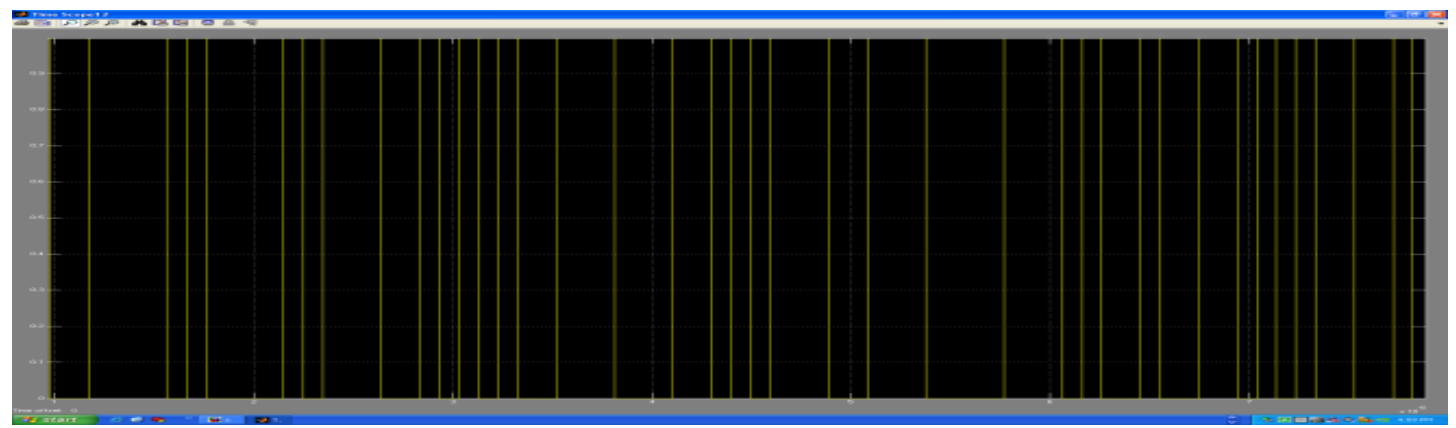

Fig. 11. PRN (Gold) Code

Generation of GPS Signal:

Figure 12 shows the final GPS signal obtained.

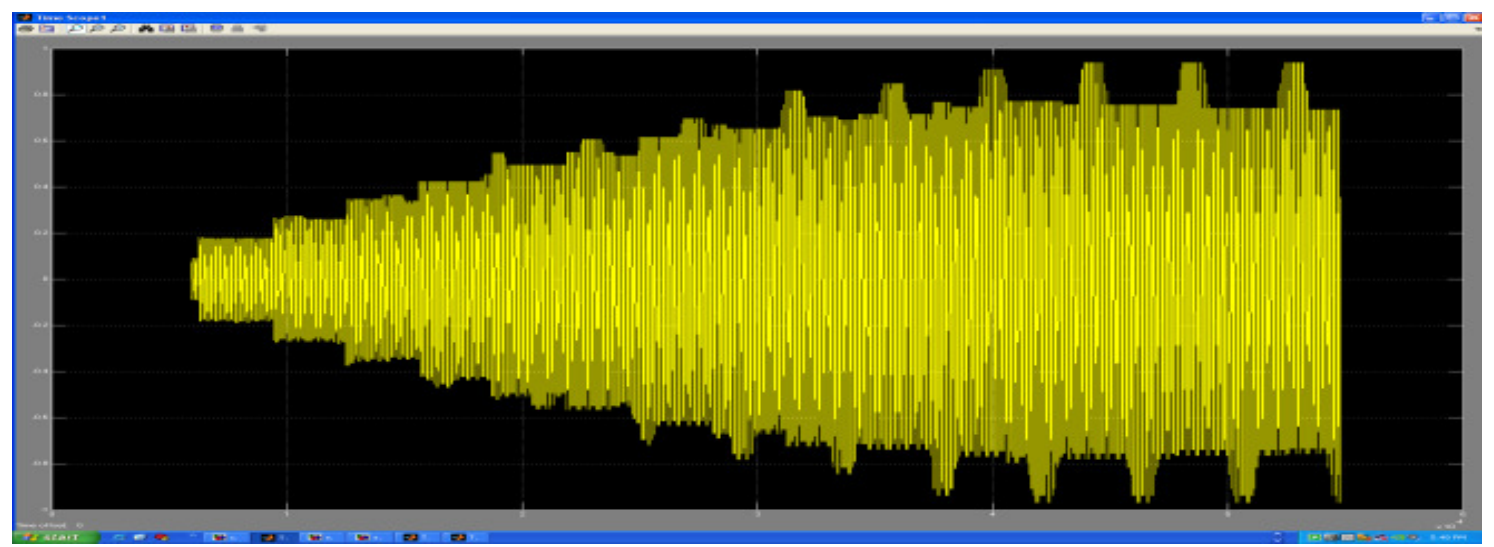

Fig. 12. GPS Signal 
Signal \& Image Processing : An International Journal (SIPIJ) Vol.3, No.6, December 2012

Currently the results are being checked for their authentication on the hardware. Once completed, real time GPS signals will be considered for further implementation of GPS receiver.

\section{CONCLUSiON}

An implementation of Digital GPS signal generator for L1 band using Lyrtech SFF-SDR board and other utilities is described. This implementation will lead to the development of indigenous GPS signal generator.

\section{ACKNOWLEDGEMENT}

The work reported in this paper is part funded by CSIR under Supra Institutional Project (SIP 21) of CEERI. We would like to thank Dr. Chandra Shekhar, Director, CSIR-CEERI, Pilani, India and Mr. Satish Mohanty Ph.D. Student, BITS, Pilani, India.

\section{REFERENCES}

[1] James Bao-Yen Tsui,"Fundamentals of Global Positioning System Receivers", 2nd edition, WileyInterscience, pp. 24, 31, 69, 70, 74, 77 and 79; 2005.

[2] Kai Borre, Akos, Nicolaj, Rinder, Jensen, "A Software Defined GPS and Galileo Receiver", Birkhauser, pp.17, 19 and 21; 2007.

[3] BPSK Modulation[Online]: Available at: http://en.wikipedia.org/wiki/Phase-shift_keying

[4] Doppler Effect[Online] Available at: http://www.usna.edu/Users/physics/ejtuchol/Chapter19.pdf

[5] Thiam Hock Tan, Global Positioning System Signal Simulation, University of Queensland, Australia, 2003.

[6] Dick Benson, "The Design and Implementation of a GPS Receiver Channel", DSP magazine, pp.52, Oct. 2005.

[7] Navstar GPS Space Segment/Navigation User Interfaces, ARINC Engineering Services, LLC, CA, USA, March 7, 2006.

[8] User's guide on Lyrtech Small Form Factor SDR Evaluation Module/Development Platform, October 2008. 